\title{
Pregnancy outcome study between Pradhan mantri surakshit matriva abhiyan service utilization group and pradhan mantri surakshit matriva abhiyan service non-utilization group: a comparative study
}

\author{
Purnima Mandal ${ }^{1}$, Jaydeb Mandal ${ }^{2 *}$
}

\author{
${ }^{1}$ College of Nursing, Kolkata Medical College, Kolkata, West Bengal, India \\ ${ }^{2}$ Department of Obstetrics and Gynaecology, Malda Medical College, West Bengal, India
}

Received: 04 June 2021

Accepted: 19 June 2021

\author{
*Correspondence: \\ Dr. Jaydeb Mandal, \\ E-mail: jaydebmandal013@gmail.com
}

Copyright: () the author(s), publisher and licensee Medip Academy. This is an open-access article distributed under the terms of the Creative Commons Attribution Non-Commercial License, which permits unrestricted non-commercial use, distribution, and reproduction in any medium, provided the original work is properly cited.

\begin{abstract}
Background: Safe pregnancy has become a social movement in our country. Almost $15 \%$ of all pregnant women can develop potentially life-threatening complications. As a result, identification of high-risk pregnancies at earliest stage will be useful in directing appropriate intervention. Hence this study was done to evaluate the betterment of pregnancy outcome of the women who had taken the adequate service of Pradhan Mantri Surakshit Matriva Abhijyan service (PMSMA) than who had not.

Method: A longitudinal study was conducted at Malda medical college during January 2019 to June 2019. 385 women selected who had taken at least three antenatal checkups (from record analysis) at PMSMA designated clinic and another 385 women selected who had not taken PMSMA services. Women of both groups were followed up their delivery events and puerperal days till discharge from hospital. Pregnancy outcomes were compared and statistical analysis of both groups were done by SSPS software.

Results: A significant outcome difference of PMSMA service utilized and non-utilized groups in respect to fetal and maternal parameters including moderate to severe anemia, (12.98\% vs $26.49 \%)$, intra uterine growth retardation (IUGR, $20.0 \%$ vs $29.87 \%$ ), hypertensive disorders in pregnancy (HDP, $8.31 \%$ vs $13.50 \%$ ), low-birth-weight $(21.30 \%$ vs $31.16 \%)$ and stillborn $(1.29 \%$ vs $2.89 \%)$ were observed.

Conclusions: This study showed positive pregnancy outcome of PMSMA utilized group than non-utilized group. Improving the availability and accessibility of quality antenatal and delivery care through PMSMA services in all our institutions, will improve pregnancy outcome.
\end{abstract}

Keywords: PMSMA, IUGR, HDP, ANC

\section{INTRODUCTION}

Data of maternal mortality ratio (MMR) in India was very high in the year 1990 with 556 women dying during child birth per thousand hundred live births as compared to the global MMR of 385 per lakh live births. Almost $15 \%$ of all the pregnant women can develop potentially lifethreatening complications, which might require skilled care with some requiring major intervention for survival. ${ }^{1}$ The WHO has reported that almost 830 women die daily as a result of complications during antenatal period and child birth. Most maternal deaths can be prevented by providing antenatal care during pregnancy and skilled care during childbirth. ${ }^{2,3}$ Maternal mortality has become a public health problem requiring urgent concerted and effective intervention at the various levels of society., Maternal complications and poor perinatal outcomes are highly associated with non-utilization of antenatal and delivery care services and poor socio-economic conditions of the patients with poorer outcomes in un-booked than 
booked patients. ${ }^{6,7}$ Whole India has made considerable reduction of maternal and infant mortality every year, approximately 44000 women still die due to pregnancy related causes and approximately 6.6 lakh infants die within the first 28 days of life, many of these deaths are preventable and many lives can be saved if quality care is provided to pregnant women during their antenatal period and high-risk factors such as severe anemia, HDP, gestational diabetes (GDM) are detected on time and managed well. Considering above all facts in spite of ongoing different maternal and child health care programs, the PMSMA was launched on $31^{\text {st }}$ July 2016 to fulfill this vision and ensure comprehensive and quality antenatal care free of cost, universally to all pregnant women on the $9^{\text {th }}$ day/HRP day of every month at the PMSMA designated clinics to ensure that every pregnant woman receives at least one checkups in $2^{\text {nd }} / 3^{\text {rd }}$ trimester of pregnancy by a doctor of OBG specialist/medical officer at designated government health facilities. If the $9^{\text {th }}$ day of the month is a Sunday/a holiday, then the designated clinic should be organized on the next working day. Identification and line-listing of high risk pregnancies based on obstetric/medical history and existing clinical conditions are done with social emphasis given on early diagnosis and adequate and appropriate management of woman with malnutrition condition like anemia as these pregnancies need extra and specialized care. ${ }^{8}$ One of the key focus areas during PMSMA is to generate demand through information, education and communication (IEC), inter-personal communication and behavior change communication (BBC) activities. Extensive use of audiovisual and print media to raise mass awareness will be an integral of IEC/BCC campaign. Auxiliary nurse midwives (ANM), ASHA and Anganwadi workers would play a pivotal role in mobilization of the community and potential beneficiaries in both rural and urban areas for availing of services during the PMSMA.

\section{Target beneficiaries}

The program aims to reach out to all pregnant women who are in $2^{\text {nd }}$ and $3^{\text {rd }}$ trimester of pregnancy.

\section{METHODS}

After taking college ethical committee's permission and informed written consent from participant mother this study was conducted in our rural based Malda medical college department of obstetrics and gynecology over the period of 6 months from $1^{\text {st }}$ January to $30^{\text {th }}$ June 2019 , by record analysis and interview with prefixed questionnaire. Randomly 385 antenatal mothers were selected as PMSMA utilized group who were admitted in antenatal ward and labour room for safe delivery and who had taken at least 3 antenatal checkups in PMSMA designated clinic in $2^{\text {nd }}$ and $3^{\text {rd }}$ trimester along with full antenatal records (excluding exclusion criteria). Similarly, 385 mothers who had taken less than 3 antenatal checkups in any established antenatal clinic were taken as PMSMA non utilized group.
All participants in both groups with single tone pregnancies having gestational age more than 28 weeks irrespective of age and gravid status admitted in our hospital for delivery were enquired on the details through pre-structured pre-validated questionnaire and detailed history were obtained which included age, socioeconomic status (APL/BPL), educational status (literate/illiterate), and antenatal checkups status in PMSMA centre or other clinic. Obstetrics history regarding weeks of gestation, gravida, chief complaints for which they were admitted as pregnancy related complications like moderate to severe anemia (when hemoglobin is $<7 \mathrm{gm} / \mathrm{dl}$ as severe anemia, 7-8.9 gm/dl hemoglobin as moderate anemia), HDP, IUGR, history of APH (Antepartum hemorrhage) were taken. They were followed on their delivery events in the form of mode of delivery, time of delivery, PPH (postpartum hemorrhage) neonatal outcome and puerperal events till discharge.

Exclusion criteria included delivery before 28 weeks of gestation, <3 checkups (PMSMA clinic) for PMSMA utilized group and multiple pregnancy.

Collected data entered in Microsoft excel and analyzed by SSPS software modern version. Chi square test and fisher exact test were performed and $\mathrm{p}$ value calculated, $\mathrm{p}<0.05$ was considered significant.

\section{RESULTS}

In our study 385 women were randomly selected as per selection criteria as PMSMA service utilized group and another 385 pregnant women of PMSMA service nonutilized group who were admitted for pregnancy complications and delivery in our department. They were studied and results were compounded.

From demographic profile of our study (Table 1) showed overall age group distribution difference of PMSMA service user and PMSMA service non- user were not significant $(p=0.13926)$. Literacy and socioeconomic status of family had an impact on PMSMA service acceptance. PMSMA service accepter women were $91.42 \%$ literate and $8.57 \%$ were illiterate, $68.83 \%$ belonged to above poverty line and $31.16 \%$ below poverty line and difference between both PMSMA accepter group and non-accepter group were statistically significant in respect to literacy $(\mathrm{p}=0.00009)$ and socioeconomic status $(\mathrm{p}=0.000024)$.

On gravida status study (Table 2) among women of PMSMA accepter group and non-accepter group no significant difference was found in respect to order of pregnancy $(\mathrm{p}=0.118066)$.

Time of delivery study (Table 3 ) reveals that preterm delivery ( $<37$ weeks gestation) were more common occurrence in PMSMA non accepter group than PMSMA accepter group $(25.45 \%$ vs $15.58 \%)$ and post-dated delivery (>40 weeks gestation) were also slightly more in 
non PMSMA group (12.47\% vs $10.91 \%)$ than PMSMA group and overall delivery timing (in weeks of gestation) difference were statistically significant ( $p$ value of $0.001328)$.

Maternal outcome study (Table 4) reflects that among PMSMA service accepters were less anemic than PMSMA service non accepters (12.98\% vs $26.49 \%)$. Incidence of HDP, IUGR were less in PMSMA service accepter group than PMSMA non accepter group and the difference of incidence of IUGR among both groups were $(20.0 \%$ vs $29.87 \%$ ) statistically significant $(\mathrm{p}=0.001549)$. Difference of other clinical conditions like APH, PPH puerperal sepsis were not marked in both groups. No maternal death was observed in PMSMA service utilization group till discharge of them from hospital, on the other hand two maternal deaths were observed in PMSMA non utilization group. One mother died due to eclampsia from severe pregnancy induced hypertension and another due to multi organ failure from severe sepsis with severe anemia.

Mode of delivery study (Table 5) reveals that normal delivery was more in PMSMA utilized group than other counterpart $(66.66 \%$ vs $50.90 \%)$ and a large percentage of women delivered by caesarean section (LUCS)in PMSMA non utilized group (42.60\% vs $31.16 \%)$. In PMSMA service utilized group $31.66 \%$ LUCS were planned beforehand (elective LUCS) and $68.33 \%$ LUCS had emergency indications. In PMSMA non utilized group more than $90 \%$ cesarean sections were done due to emergency indications ( $91.46 \%$ vs $8.53 \%$ emergency LUCS and elective LUCS respectively). Instrumental delivery and assisted vaginal delivery percentage were also more in non PMSMA group and the mode of delivery difference was statistically significant $(\mathrm{p}=0.000994)$.

Neonatal outcome study (Table 6) depicts those babies born underweight $(<2.5 \mathrm{~kg})$ were common occurrence in PMSMA non utilization group $(31.16 \%$ vs $21.30 \%)$. Overall birth weight difference of both groups was statistically significant $(\mathrm{p}=0.007504)$. Incidence of moderate to severe birth asphyxia were more common in non PMSMA group (4.6\% vs $2.85 \%$ ).

Intra uterine fetal death and still born babies were more in non PMSMA group $(2.85 \%$ vs $1.29 \%)$ though the difference was not statistically significant.

Table 1: Demographic profile.

\begin{tabular}{|c|c|c|c|c|c|c|}
\hline \multirow{2}{*}{ Demographic profiles } & \multicolumn{2}{|c|}{ PMSMA group } & \multicolumn{2}{|c|}{ Non PMSMA group } & \multirow{2}{*}{$\mathbf{X}^{2}$} & \multirow{2}{*}{ P value } \\
\hline & No. & Percentage (\%) & No. & Percentage $(\%)$ & & \\
\hline \multicolumn{7}{|l|}{ Age (years) } \\
\hline$<19$ & 101 & 26.24 & 126 & 32.27 & \multirow{3}{*}{3.9428} & \multirow{3}{*}{0.13926} \\
\hline $19-30$ & 204 & 52.98 & 188 & 48.48 & & \\
\hline$>30$ & 80 & 20.78 & 71 & 18.44 & & \\
\hline \multicolumn{7}{|l|}{ Literacy } \\
\hline Literate & 352 & 91.42 & 315 & 81.81 & \multirow{2}{*}{15.343} & \multirow{2}{*}{0.00009} \\
\hline Illiterate & 33 & 8.57 & 70 & 18.18 & & \\
\hline \multicolumn{7}{|l|}{ Family income (Rs.) } \\
\hline *APL & 265 & 68.83 & 208 & 54.02 & \multirow{2}{*}{17.8083} & \multirow{2}{*}{0.000024} \\
\hline * BPL & 120 & 31.16 & 177 & 45.97 & & \\
\hline
\end{tabular}

*APL=Above poverty line, $* \mathrm{BPL}=$ Below poverty line.

Table 2: Gravida status.

\begin{tabular}{|lllll|l}
\multirow{2}{*}{ Gravida } & \multicolumn{2}{l}{ PMSMA group } & \multicolumn{2}{l}{ Non PMSMA group } & P value \\
\cline { 1 - 5 } & No. & Percentage (\%) & No. & Percentage (\%) & \multirow{2}{*}{0.118066} \\
\cline { 1 - 5 } Primigravida & 134 & 34.80 & 155 & 40.25 & 59.74 \\
\end{tabular}

Table 3: Time of delivery.

\begin{tabular}{|c|c|c|c|c|c|c|}
\hline \multirow{2}{*}{$\begin{array}{l}\text { Gestational age } \\
\text { (weeks) }\end{array}$} & \multicolumn{2}{|c|}{ PMSMA group } & \multicolumn{2}{|c|}{ Non PMSMA group } & \multirow{2}{*}{$\mathbf{X}^{2}$} & \multirow{2}{*}{$P$ value } \\
\hline & No. & Percentage $(\%)$ & No. & Percentage (\%) & & \\
\hline$<37$ & 60 & 15.58 & 98 & 25.45 & \multirow{3}{*}{13.2481} & \multirow{3}{*}{0.001328} \\
\hline $37-40$ & 283 & 73.50 & 239 & 62.07 & & \\
\hline$>40$ & 42 & 10.91 & 48 & 12.47 & & \\
\hline
\end{tabular}


Table 4: Maternal outcome study.

\begin{tabular}{|llllll|}
\hline $\begin{array}{l}\text { Maternal } \\
\text { complications }\end{array}$ & No. & Percentage (\%) & No. & Percentage (\%) & P value \\
\hline $\begin{array}{l}\text { Moderate to severe } \\
\text { anemia }\end{array}$ & 50 & 12.98 & 102 & 26.49 & 0.00001 \\
\hline HDP & 32 & 8.31 & 52 & 13.50 & 0.020782 \\
\hline IUGR & 77 & 20.0 & 115 & 29.87 & 0.001549 \\
\hline APH & 36 & 9.35 & 40 & 10.38 & 0.2336 \\
\hline PPH & 20 & 5.19 & 26 & 6.75 & 0.20080 \\
\hline Puerperal sepsis & 32 & 8.42 & 48 & 12.46 & 0.0587 \\
\hline Maternal death & 00 & 0 & 2 & 0.519 & \\
\hline
\end{tabular}

Table 5: Mode of delivery.

\begin{tabular}{|c|c|c|c|c|c|c|}
\hline \multirow{2}{*}{ Mode of delivery } & \multicolumn{2}{|c|}{ PMSMA group } & \multicolumn{2}{|c|}{ Non PMSMA group } & \multirow{2}{*}{$\mathbf{X}^{2}$} & \multirow{2}{*}{ P value } \\
\hline & No. & Percentage (\%) & No. & Percentage (\%) & & \\
\hline Normal & 247 & 66.66 & 196 & 50.90 & \multirow{5}{*}{13.8278} & \multirow{5}{*}{0.000994} \\
\hline Assisted & 18 & 4.67 & 25 & 6.50 & & \\
\hline LUCS & 120 & 31.16 & 164 & 42.60 & & \\
\hline Emergency & 82 & 68.33 & 150 & 91.46 & & \\
\hline Elective & 38 & 31.66 & 14 & 08.53 & & \\
\hline
\end{tabular}

Table 6: Neonatal outcome study.

\begin{tabular}{|c|c|c|c|c|c|c|}
\hline \multirow{2}{*}{ Neonatal outcomes } & \multicolumn{2}{|c|}{ PMSMA group } & \multicolumn{2}{|c|}{ Non PMSMA group } & \multirow{2}{*}{$\mathbf{X}^{2}$} & \multirow{2}{*}{$P$ value } \\
\hline & No. & Percentage $(\%)$ & No. & Percentage (\%) & & \\
\hline \multicolumn{7}{|l|}{ Birth weight (kg) } \\
\hline$<2.5$ & 82 & 21.30 & 120 & 31.16 & \multirow{3}{*}{9.7845} & \multirow{3}{*}{0.007504} \\
\hline $2.5-3.5$ & 265 & 68.83 & 234 & 60.78 & & \\
\hline$>3.5$ & 38 & 9.87 & 31 & 8.05 & & \\
\hline $\begin{array}{l}\text { Moderate to severe } \\
\text { asphyxia }\end{array}$ & 11 & 2.85 & 18 & 4.6 & 1.7558 & 0.18515 \\
\hline Still born & 5 & 1.29 & 11 & 2.85 & 2.2977 & 1.2956 \\
\hline
\end{tabular}

*Apgar score 0-3=severe asphyxia, Apgar score 4-6=severe asphyxia.

\section{DISCUSSION}

High risk pregnancy can have serious maternal, obstetric and neonatal complications if left undetected. Government of India has introduced several schemes for early detection and management of high-risk pregnancy with recent one being "PMSMA" services. In our study $91.42 \%$ literate people and $8.57 \%$ illiterate people utilized PMSMA service and $68.83 \%$ APL population and $31.16 \%$ BPL population utilized PMSMA service. Which showed that women's education and higher socioeconomic status both were strong determinant for utilization of PMSMA service. Our study was comparable to various studies. ${ }^{9}$ In our study distribution of moderate to severe anemia (26.49 vs $12.98 \%$ ), incidence of the IUGR (29.87 vs $20.0 \%)$ and low birth weight baby(31.16\% vs $21.30 \%)$ were fairly common in PMSMA service non-utilized group and results were statistically significant. This study was similar to the study of Sinha, where outcome of pregnancy in terms of perinatal death, low-birth weight (19.2\%) and maternal deaths improve significantly for women who have at least two antenatal check-ups. ${ }^{10}$ Regarding mode of delivery in our study cesarean section was more common findings in PMSMA non utilized group (42.60 vs $31.16 \%$ ) assisted vaginal and instrumental deliveries were also more in PMSMA non utilized group. The similar type of study by Aggarwal et al, where cesarean section was more common in un-booked cases $(40.8 \%)$ as compared to (33.8\%) booked cases. ${ }^{11}$ Amir et al un booked mothers had greater rate of cesarean section as compared to booked mothers $(31.5 \%$ vs $19.6 \%$ respectively, $p=0.001) .{ }^{12}$ The reasons behind this could be the PMSMA service utilized group had less complicated pregnancy like HDP, IUGR, APH etc., than PMSMA non utilized group. When we analyzed neonatal outcome, low birth weight $(31.16 \%$ vs $21.30 \%)$ and pre term newborn (21.03\% vs $16.62 \%)$ respectively were more prevalent among PMSMA non utilized group than PMSMA utilized group. This study is supported by another study by Sodje et al. ${ }^{13}$ Intra uterine death of fetus was significantly less among PMSMA utilized group than PMSMA non utilized group. It is less than two times (1.29 vs $2.85 \%$ ) in PMSMA utilized group 
than non-utilized group. These findings corroborate the study of Chigbu et al. ${ }^{14}$ From this study incidence of lowbirth-weight babies, preterm babies and still born babies are less common observation in PMSMA utilized group probably as because of nutritional supplementation, anemia, hypertension correction and timely termination of high-risk pregnancy in regular PMSMA service utilized group. No maternal death was observed among 385 women of PMSMA utilized group. Two maternal deaths were observed from PMSMA non utilized group due to timely non detection of high-risk factors and optimum treatment during antenatal period because of nonattendance at PMSMA clinic or any other clinic. However, the study has its own limitations, since the main part of this study is record based, we relied on the data recorded in PMSMA entry card. There could be errors in entering data of the pregnant women by stake holders.

\section{CONCLUSION}

Based on the above findings in our study overall maternal and neonatal complications are significantly higher in PMSMA service non utilized group. Teenage pregnancy ( $<19$ years) may be avoided with adequate proper family planning counseling. Severe anemia hypertensive pregnancy complications, IUGR baby, preterm labour, low birth weight babies IUFD can be avoided in many instances if high risk factor detection and timely adequate treatment be given to incumbent via different government services. India is committed to reducing preventable maternal death through concerted efforts and public private partnership. Comprehensive and quality antenatal checkups and identification and follow up of high-risk pregnancy through different services can reduce significant maternal and neonatal mortality and morbidity. In the light of this knowledge, we may conclude PMSMA services play a very important role as an add on government initiative to our current program under maternal and child health care $(\mathrm{MCH})$.

\section{ACKNOWLEDGMENTS}

Authors would like to thanks to all participant mothers in study. And would like to thank the juniors who helped a lot for conducting this study. Also, like to extend sincere gratitude to staffs of antenatal ward, postnatal ward and labour room of Malda medical college for their constant support in supplying the right kind of data for our study.

Funding: No funding sources

Conflict of interest: None declared

Ethical approval: The study was approved by the Institutional Ethics Committee

\section{REFERENCES}

1. Managing Complications in pregnancy and childbirth: A Guide for midwives and Doctors. $2^{\text {nd }}$ ed Geneva: World Health Organization. 2017.

2. United nation New York. The Sustainable Developmental Goals Report. 2017;21.

3. Ansary R, Anisujjama M. Factors Determining Patterns of United Need for Family Planning in Uttar Pradesh, India. Int Res J Social Sci. 2012;1(u):16-23.

4. Ekele BA, Audu LR. Gestational age at first antenatal attendance in Sokoto. Northern Nigeria. Tror J obste Gnaecol. 1998;15:39-40.

5. Abonzehar C, Royston E. Maternal mortality: a Global text book Geneva; World Health Organization. 1991;9-602.

6. Abonzahr C, Wardlaw T, Stanton C, Hill K. Maternal mortality. World Health StatQ. 1996;49:77-87.

7. Ogunniyi SO, Faleyimu BL. Trends in maternal deaths in Ilesa, Nigeria, 1977-1988. West Afr J Med. 1991;10:400-4.

8. Maternal Health Division, Ministry of Health and Family Welfare, Government of India, Pradhan Mantri Surakshit Matriva Abhiyan. 2016;2.

9. Mattews Z, Mahendra S, Kilaru A, Ganapathy S. Antenatal care servicing and morbidity in rural Karnataka, India. Result of a prospective study Assia Oacific Pop J. 2001;16(2):11-8.

10. Sinha S. Outcome of Antenatal Care in an Urban Slum of Delhi: Indian J. Commun Med.2006;21:111-5.

11. Onwudiegwu U. The of a depressed economy to the utilization of maternal health services. The Nigerean experience. J Obstet Gynaecol. 1993;13:311-4:11.

12. Fawcus SR, Crowther CA, Van Baelen P, Marumakhoke J. Booked and un-booked mothers delivery at Harare Maternity Hospital Zimbabwe. A comparison of maternal characteristic and fetal outcome. Cent Afr J Med 1992;38(1):402-8.

13. Sodje JDK, Ande AAB. Socio demographic characteristics and pregnancy Outcome of booked and un-booked women at the University of Benin Teaching hospital JMBR. 2016;15(1):109-20.

14. Chibu B, Onwere S, Kamaru CL, Aluks C, Okoro O, Adibe E. Pregnancy outcome in booked and unbooked mothers in South Estern Nigeria. East Afr Med J. 2009;68(6):267-71.

Cite this article as: Mandal P, Mandal J. Pregnancy outcome study between Pradhan Mantri Surakshit Matriva Abhiyan service utilization group and Pradhan Mantri Surakshit Matriva Abhiyan service non-utilization group: a comparative study. Int J Reprod Contracept Obstet Gynecol 2021;10:2651-5. 